National Marine

Fisheries Service

NOAA
Fishery Bulletin

ar established in 1881 o
Spencer F. Baird

First U.S. Commissione of Fisheries and founder of Fishery Bulletin
Abstract-Nine microsatellite loci isolated in saffron cod (Eleginus gracilis) have potential applications for population genetics. Polymerase chain reaction products of samples of $E$. gracilis from northwestern Alaska amplified reliably, produced only one or two microsatellite bands, and had no apparent homozygote excess. A collection of $E$. gracilis sampled in the Gulf of Alaska (GOA) near Kodiak Island did not amplify reliably at one locus, and allele frequency profiles clustered distinctly (with principal component analysis [PCA]) from the northwestern Alaska collection. Northwestern Alaska and GOA $E$. gracilis collections were genetically different (on the basis of a standardized genetic differentiation measure $\left[G^{\prime}{ }_{\mathrm{ST}}\right]=0.313$, chord distance $\left[D_{\text {chord }}\right]=0.078, P<0.0001$ ) and differed in expected average heterozygosities at shared loci ( 0.859 and 0.689 , respectively). We tested the microsatellite primers on other gadid species endemic to the northern Pacific Ocean, Bering Sea, and Arctic Ocean for cross-species amplification. Not all loci amplified reliably in navaga (E. nawaga), $\mathrm{Pa}-$ cific tomcod (Microgadus proximus), Arctic cod (Boreogadus saida), Pacific cod (Gadus macrocephalus), or walleye pollock (G. chalcogrammus). Reliable loci varied in microsatellite size profiles and produced distinct PCA clusters and accurate genotype assignments that allowed accurate species identification. The identifications support previous morphological and genetically determined systematic classifications and distinguished the geographically separated collections of $E$. gracilis.

Manuscript submitted 20 April 2017. Manuscript accepted 7 November 2017. Fish. Bull. 116:60-68 (2018)

Online publication date: 13 December 2017. doi: 10.7755/FB.116.1.6

The views and opinions expressed or implied in this article are those of the author (or authors) and do not necessarily reflect the position of the National Marine Fisheries Service, NOAA.

\title{
Distinction of saffron cod (E/eginus gracilis) from several other gadid species by using microsatellite markers
}

\author{
Noel Sme ${ }^{1}$ \\ Sarah Lyon' \\ Michael Canino ${ }^{2}$ \\ Natalia Chernova ${ }^{3}$ \\ Jason O'Bryhim ${ }^{4}$ \\ Stacey Lance ${ }^{4}$ \\ Kenneth Jones $^{5}$ \\ Franz Mueter $^{1}$ \\ Anthony Gharrett (contact author) ${ }^{1}$
}

Email address for contact author: a.gharrett@alaska.edu

1 Juneau Center

College of Fisheries and Ocean Sciences

University of Alaska Fairbanks

17101 Point Lena Loop Road

Juneau, Alaska 99801

2 Alaska Fisheries Science Center

National Marine Fisheries Service, NOAA

7600 Sand Point Way NE

Seattle, Washington 98115

3 Zoological Institute of the Russian

Academy of Sciences

Universitetskaja Naberezhnaya 1
4 Savannah River Ecology Laboratory University of Georgia

P.O. Drawer E

Aiken, South Carolina 29802

5 Section of Hematology-Oncology

Department of Pediatrics

University of Colorado School of Medicine

12800 East $19^{\text {th }}$ Ave, RC-1 North, Room 4129

Aurora, Colorado 80045

St. Petersburg, Russia 199034
The saffron cod (Eleginus gracilis) is a gadid fish distributed from the northern Gulf of Alaska (GOA), around the Pacific Rim into the Sea of Okhotsk, and into the Arctic Ocean abutting the North Pacific Ocean (Cohen et al., 1990; Mecklenburg et al., 2016). Mature fish, which generally exceed $20 \mathrm{~cm}$ in fork length (FL) and may grow to more than $50 \mathrm{~cm} \mathrm{FL}$, are eaten by indigenous Alaskans and in Asia and have potential for commercial harvest in North America (Cohen et al., 1990; NPFMC1; Love et al. ${ }^{2}$ ).

${ }^{1}$ NPFMC (North Pacific Fisheries Management Council). 2009. Fishery management plan for fish resources of the Arctic management area, $76 \mathrm{p}$. NPFMC, Anchorage, AK. [Available from website.]

${ }^{2}$ Love, M. S., N. Elder, C. W. Mecklen-
Saffron cod is also an important component of the Arctic ecosystem (Wolotira, 1985; Copeman et al., 2016; Love et al. ${ }^{2}$ ) and is a significant prey item for several marine mammals (Bluhm and Gradinger, 2008). It is thought to compete for food with Arctic cod (Boreogadus saida) and may have a competitive advantage as sea ice changes occur in response to climate change (Love et al. ${ }^{2}$ ). The species, especially in North Ameri-

burg, L. K. Thorsteinson, and T. A. Mecklenburg. 2016. Alaska Arctic marine fish species accounts: saffron cod (Eleginus gracilis). In Alaska Arctic marine fish ecology catalog. U.S. Geological Survey Sci. Invest. Rep. 2016-5038 (OCS Study, BOEM 2016-048) (L. K. Thorsteinson and M. S. Love, eds.), p. 201-208. [Available from website.] 
can waters, is little studied, but its position in the food web, potential population responses to warming and reduction of sea ice in the Arctic, and proposed offshore oil and gas development make learning about this species imperative.

The distributions of several other gadid speciesArctic cod (B. saida), Pacific cod (Gadus macrocephalus), walleye pollock (Gadus chalcogrammus), and Pacific tomcod (Microgadus proximus)—overlap with that of $E$. gracilis, and furthermore navaga (Eleginus nawaga) from the western Arctic Ocean is a congener of $E$. gracilis. Small gadids of several species are very similar morphologically and often present challenges for identification. The morphological bases of gadiform taxonomy, including the subfamily Gadinae to which all of the species in our study belong, have been described (e.g., Schultz and Welander, 1935; Svetovidov, 1948; Cohen, 1989), as have the phylogenetic relationships among gadiform families (e.g., Roa-Varón and Ortí, 2009) and within Gadinae (Teletchea et al., 2006). However, questions remain about the relationships among E. gracilis, E. nawaga, and M. proximus (e.g., Carr et al., 1999; Roa-Varón and Ortí, 2009). Moreover, the modern geographic separation between $E$. eleginus and $E$. nawaga, if any exists, is unknown.

Genetic analyses of a species can provide insight into several facets of its biology, including population structure, life history (e.g., Kamin et al., 2014), and recent demographic history (e.g., Harpending et al., 1998). Information about population structure can be obtained from surveys in different geographic regions and the fish tested for genetic variation. Microsatellite data are beneficial, when compared with other classes of molecular markers, in that they are often highly polymorphic in fish species (DeWoody et al., 2000) and are relatively inexpensive to apply. Consequently, microsatellite markers were isolated from and developed for E. gracilis. Here we 1) examine their variability in two $E$. gracilis collections from geographically separated areas; 2) determine their cross-reactivity with other northern Pacific and Arctic ocean gadids and the ability of suites of these loci to accurately distinguish among species; and 3) evaluate differences in the allele profiles among $M$. proximus, $E$. nawaga, and the two collections of $E$. gracilis.

\section{Materials and methods}

\section{Samples and DNA isolation}

Collections of $E$. gracilis were collected from the Chuckchi Sea in 2011 and near Kodiak Island, Alaska, in 2013. Collections of B. saida from the Chukchi Sea were made in 2012 and collections of $E$. nawaga were collected from the Barents Sea in 2013. In 2015, G. chalcogrammus were collected in the southeast Bering Sea. Two collections of $M$. proximus were obtained, one from Puget Sound, Washington, between 1997 and 1999, and one from Prince William Sound, Alaska, in
2012. Two collections of $G$. microcephalus were collected in 2013, one collected from Puget Sound and the other from Unimak Pass in the northern Gulf of Alaska (see details for all collections in Table 1).

Tissue samples were preserved in a DNA preservative solution (Seutin et al., 1991) or 95\% ethanol and stored in the laboratory at $-20^{\circ} \mathrm{C}$. Total cellular DNA was isolated with Gentra Puregene ${ }^{3}$ or Qiagen DNeasy kits (Qiagen, Hilden, Germany) by following the manufacturer's instructions.

\section{Discovery of microsatellites}

An Illumina paired-end shotgun library (Illumina, Inc., San Diego, CA) was prepared by shearing $1 \mu \mathrm{g}$ of DNA from a single $E$. gracilis Chukchi Sea individual with a Covaris S220 focused-ultrasonicator (Covaris, Inc., Woburn, MA). The standard protocol for the TruSeq DNA library kit (Illumina, Inc.) and a multiplex identifier adaptor index were used (see e.g., Stoutamore et al., 2012). A HiSeq system (Illumina, Inc.) was used to sequence 100-base pair [bp] paired-end readings. The program PAL_FINDER, vers. 0.02.03 (Castoe et al., 2012) was used to analyze 5 million of the resulting sequences to identify readings that had di-, tri-, tetra-, penta-, and hexanucleotide repeat motifs. The data are archived in the Sequence Read Archive of the National Center for Biotechnology Information under accession number SAMN06333955. Once positive reads were identified, oligonucleotide primers were designed with the program Primer3, vers. 2.0.0 (Koressaar and Remm, 2007; Untergasser et al., 2012). To avoid issues with copy number of primer sequences in the genome, loci for which the primer sequences occurred only once or twice in the 5 million reads were selected. Fortyeight presumed loci from $E$. gracilis that met this criterion were chosen for primer design.

The 48 primer pairs were tested with DNA from 8 $E$. gracilis individuals. The polymerase chain reactions (PCRs) were conducted over two $10^{\circ} \mathrm{C}$ spans of annealing temperatures $\left(65-55^{\circ} \mathrm{C}\right.$ or $\left.58-48^{\circ} \mathrm{C}\right)$ with touchdown thermal cycling profiles (Don et al., 1991). The results (not presented) were analyzed with GeneMapper, vers. 3.7 (Thermo Fisher Scientific, Waltham, MA). Eighteen primer pairs were then selected for evaluation with larger sample sizes.

\section{Analysis of microsatellites}

Target sequences of the 18 primer pairs amplified with a touchdown PCR strategy reduced nontarget bands in the product spectrum (Don et al., 1991). All reactions contained $\sim 1$ unit Taq polymerase, $1 \times$ PCR buffer $\left(50 \mathrm{mM} \mathrm{KCl}_{2}, 10 \mathrm{mM}\right.$ Tris-HCl pH 9.0, 0.1\% Triton X-100; Promega Corp., Madison, WI), $0.5 \mu \mathrm{M}$ deoxyribonucleotide triphosphates, and 0.025 to $0.1 \mu \mathrm{g}$ DNA

\footnotetext{
${ }^{3}$ Mention of trade names or commercial companies is for identification purposes only and does not imply endorsement by the National Marine Fisheries Service
} 


\section{Table 1}

Number of samples $(n)$, geographic regions, gear used, collector (when known) and collector's affiliation for collections of 6 gadid species sampled in this study: saffron cod (Eleginus gracilis), navaga (E. nawaga), Pacific tomcod (Microgadus proximus), Pacific cod (Gadus macrocephalus), walleye pollock (G. chalcogrammus), and Arctic cod (Boreogadus saida). Asterisks denote specimens originally identified in the field as saffron cod, but were later re-examined.

\begin{tabular}{|c|c|c|c|c|c|}
\hline Species & Scientific name & $n$ & Geographic region & Latitude & Longitude \\
\hline \multirow[t]{2}{*}{ Saffron cod } & \multirow[t]{2}{*}{ Eleginus gracilis } & 30 & Chukchi Sea & $66.91^{\circ} \mathrm{N}$ & $162.55^{\circ} \mathrm{W}$ \\
\hline & & 41 & Gulf of Alaska & $57.73^{\circ} \mathrm{N}$ & $152.51^{\circ} \mathrm{W}$ \\
\hline Nawaga & Eleginus nawaga & 81 & Barents Sea & $69.04^{\circ} \mathrm{N}$ & $57.87^{\circ} \mathrm{E}$ \\
\hline \multirow[t]{2}{*}{ Pacific tomcod } & Microgadus proximus & 8 & Puget Sound & $47.71^{\circ} \mathrm{N}$ & $122.52^{\circ} \mathrm{W}$ \\
\hline & & 15 & Prince William Sound* & $60.87^{\circ} \mathrm{N}$ & $147.19^{\circ} \mathrm{W}$ \\
\hline \multirow[t]{2}{*}{ Pacific cod } & \multirow{2}{*}{ Gadus macrocephalus } & 5 & Puget Sound & $48.40^{\circ} \mathrm{N}$ & $124.41^{\circ} \mathrm{W}$ \\
\hline & & 8 & Unimak Pass & $54.45^{\circ} \mathrm{N}$ & $164.99^{\circ} \mathrm{W}$ \\
\hline \multirow{3}{*}{$\begin{array}{l}\text { Walleye pollock } \\
\text { Arctic cod }\end{array}$} & Gadus chalcogrammus & 6 & SE Bering Sea & $55.67^{\circ} \mathrm{N}$ & $163.33^{\circ} \mathrm{W}$ \\
\hline & \multirow[t]{2}{*}{ Boregadus saida } & 39 & Chukchi Sea & $66.90^{\circ} \mathrm{N}$ & $162.59^{\circ} \mathrm{W}$ \\
\hline & & 14 & Chukchi Sea* & $66.90^{\circ} \mathrm{N}$ & $162.59^{\circ} \mathrm{W}$ \\
\hline Species & Date & Gear & Collector & & \\
\hline \multirow[t]{2}{*}{ Saffron cod } & $9 / 11$ & jig & A. Whiting & \multicolumn{2}{|c|}{ Native Village of Kotzebue } \\
\hline & $6 / 7 / 2013$ & rod and reel & E. Munk & \multirow{2}{*}{\multicolumn{2}{|c|}{$\begin{array}{l}\text { NOAA Fisheries } \\
\text { Russian Academy of Sciences }\end{array}$}} \\
\hline \multirow{3}{*}{$\begin{array}{l}\text { Navaga } \\
\text { Pacific tomcod }\end{array}$} & $7 / 13$ & trawl & N. Chernova & & \\
\hline & 3/1997-8/1999 & beach seine & M Canino & \multicolumn{2}{|c|}{ NOAA Fisheries } \\
\hline & $7 / 12$ & beach seine & M. Arimitsu & \multicolumn{2}{|c|}{ U.S. Geological Survey } \\
\hline \multirow[t]{2}{*}{ Pacific cod } & $3 / 13$ & beach seine & M. Canino & \multicolumn{2}{|c|}{ NOAA Fisheries } \\
\hline & $3 / 13$ & trawl & M. Canino & \multicolumn{2}{|c|}{ NOAA Fisheries } \\
\hline \multirow{3}{*}{$\begin{array}{l}\text { Walleye pollock } \\
\text { Arctic cod }\end{array}$} & $9 / 15$ & trawl & W. Strasburger & \multicolumn{2}{|c|}{ NOAA Fisheries } \\
\hline & $4 / 12$ & jig & A. Whiting & \multirow{2}{*}{\multicolumn{2}{|c|}{ Native Village of Kotzebue }} \\
\hline & $4 / 12$ & jig & A. Whiting & & \\
\hline
\end{tabular}

template. Fluorescent primers labeled with an IRDye infrared dye $(10 \mu \mathrm{g} / \mathrm{mL}$; Integrated DNA Technologies, Inc., Coralville, IA) were included in the reactions. The amplification profiles for each locus were the following: denaturation at $95^{\circ} \mathrm{C}$ for $5 \mathrm{~min} ; 20$ touchdown cycles at $95^{\circ} \mathrm{C}$ for $30 \mathrm{~s}$, annealing temperatures ranging from 62 to $52^{\circ} \mathrm{C}$ (touchdown) for $30 \mathrm{~s}$ (decreased $0.5^{\circ} \mathrm{C}$ per cycle), and $72^{\circ} \mathrm{C}$ for $30 \mathrm{~s}$; then 15 cycles of $95^{\circ} \mathrm{C}$ for 30 $\mathrm{s}$, the lowest annealing temperature $\left(55^{\circ} \mathrm{C}\right)$ for $30 \mathrm{~s}$, and $72^{\circ} \mathrm{C}$ for $30 \mathrm{~s}$, and a final extension at $72^{\circ} \mathrm{C}$ for 5 minutes.

Approximately $1 \mu \mathrm{L}$ of amplified PCR product and stop buffer (95\% formamide, $0.1 \%$ bromophenol blue) was loaded onto a $0.25 \mathrm{~mm} 6 \%$ acrylamide gel (PAGEPLUS $^{\mathrm{TM}}$, Amresco, Solon, $\mathrm{OH}$ ) and fragments were separated in $1 \times$ TBE buffer (0.09 M Tris-Borate, $2 \mathrm{mM}$ EDTA, pH 8) at $1500 \mathrm{~V}$ with a 4300 DNA Analyzer (LICOR, Inc., Lincoln, NE). Electrophoresis times varied from 2 to 3 hours depending on allele sizes of the PCR product. The image of the PCR product was analyzed with SAGA, vers. 3.1 (LI-COR, Inc.) software. Two individuals scored each gel separately and samples that differed in recorded allele size were genotyped a second or third time.

\section{Analysis of data}

Two collections of $E$. gracilis (one from the Chukchi Sea and another from near Kodiak Island, Alaska) were examined separately (Table 1). Collections of B. saida from the Chukchi Sea were combined for analysis as a single species as were collections of $M$. proximus (Prince William Sound and Puget Sound), and of G. macrocephalus (Puget Sound and Unimak Pass) (Table 1).

Allele frequencies and expected unbiased heterozygosities were estimated and genotype frequencies were tested for departures from Hardy-Weinberg expectations with GENEPOP, vers. 4.5.1 (Rousset, 2008). Significance of multiple tests was confirmed with sequential Bonferroni tests (Rice, 1989) and false discovery rate (FDR; Benjamini and Hochberg, 1995) corrections. Genotypes of individuals that produced deviations from Hardy-Weinberg expectations or apparent principal component analysis (PCA) outliers were reconfirmed by additional genotyping.

Two genetic distances that are not strongly influenced by the numbers of alleles at a locus, but that are based on very different algorithms, were estimated. The standardized genetic differentiation measure $G^{\prime}{ }_{\mathrm{ST}}$ 


\section{Table 2}

Microsatellite properties of northern gadid species of the Pacific Rim and Arctic Ocean for the 9 loci designed for saffron cod (Eleginus gracilis) sampled in the Chukchi Sea and Gulf of Alaska (GOA) in 2011 and 2013. Number of samples for each species $(n)$, the numbers of different allele observed $\left(n_{\mathrm{a}}\right)$, the range of allele sizes, the mean and standard error of the mean (SE) of allele sizes, expected heterozygosities $\left(H_{\mathrm{e}}\right)$, and inbreeding coefficients $\left(F_{\text {is }}\right)$ are given. An entry of dna means the locus did not reliably amplify. Collections were made in 2013 for navaga $(E$. nawaga), during 1997-1999 for Pacific tomcod (Microgadus proximus), in 2013 for Pacific cod (Gadus macrocephalus), in 2015 for walleye pollock (G. chalcogrammus), and in 2012 for Arctic cod (Boreogadus saida).

\begin{tabular}{|c|c|c|c|c|c|c|}
\hline Locus and species & $n$ & $n_{\mathrm{a}}$ & range & mean & $H_{\mathrm{e}}$ & $F_{\text {is }}$ \\
\hline \multicolumn{7}{|l|}{ Elgr07 } \\
\hline Chukchi Sea E. gracilis & 30 & 10 & $127-175$ & $155.7(1.2)$ & 0.867 & -0.016 \\
\hline GOA $E$. gracilis & 41 & 7 & $151-179$ & $160.6(0.5)$ & 0.683 & -0.054 \\
\hline E. nawaga & 81 & 14 & $115-183$ & $133.7(0.7)$ & 0.815 & -0.028 \\
\hline M. proximus & 22 & 1 & 123 & $123.0(0.0)$ & 0.000 & - \\
\hline G. macrocephalus & 14 & 2 & 115 and 131 & $128.7(1.1)$ & 0.286 & -0.130 \\
\hline G. chalcogrammus & 6 & 2 & 131 and 135 & $133.3(0.6)$ & 0.833 & -0.667 \\
\hline B. saida & 53 & dna & - & - & - & - \\
\hline \multicolumn{7}{|l|}{ Elgr11 } \\
\hline Chukchi Sea $E$. gracilis & 30 & 12 & $208-272$ & $222.1(1.7)$ & 0.833 & 0.043 \\
\hline GOA $E$. gracilis & 41 & 8 & $204-260$ & $214.0(1.3)$ & 0.634 & -0.117 \\
\hline E. nawaga & 81 & 21 & $240-336$ & $274.7(1.4)$ & 0.877 & 0.043 \\
\hline M. proximus & 22 & 17 & $248-340$ & $285.8(3.0)$ & 0.727 & $0.230^{\mathrm{a}}$ \\
\hline G. macrocephalus & 14 & 18 & $192-204$ & $202.9(0.6)$ & 0.286 & -0.072 \\
\hline G. chalcogrammus & 6 & dna & - & - & - & - \\
\hline B. saida & 53 & dna & - & - & - & - \\
\hline \multicolumn{7}{|l|}{ Elgr31 } \\
\hline Chukchi Sea $E$. gracilis & 30 & 6 & $191-211$ & $197.1(0.7)$ & 0.833 & -0.103 \\
\hline GOA $E$. gracilis & 41 & 4 & $191-203$ & $194.8(0.5)$ & 0.659 & -0.015 \\
\hline E. nawaga & 81 & 11 & $179-231$ & $204.4(0.8)$ & 0.864 & -0.052 \\
\hline M. proximus & 22 & 14 & $215-267$ & $240.5(2)$ & 0.955 & -0.027 \\
\hline G. macrocephalus & 14 & 18 & $223-299$ & $263.3(3.7)$ & 1.000 & -0.034 \\
\hline G. chalcogrammus & 6 & 10 & $215-267$ & $241.7(4.8)$ & 1.000 & -0.035 \\
\hline B. saida & 53 & 37 & $223-543$ & $355.6(7.6)$ & 0.962 & 0.005 \\
\hline \multicolumn{7}{|l|}{ Elgr38 } \\
\hline Chukchi Sea E. gracilis & 30 & 9 & $112-144$ & $127.5(1.1)$ & 0.867 & -0.026 \\
\hline GOA $E$. gracilis & 41 & dna & - & - & - & - \\
\hline E. nawaga & 81 & dna & - & - & - & - \\
\hline M. proximus & 22 & 6 & $120-140$ & $127.9(0.8)$ & 0.727 & 0.068 \\
\hline G. macrocephalus & 14 & 6 & $128-160$ & $141.9(1.9)$ & 0.786 & 0.037 \\
\hline G. chalcogrammus & 6 & 7 & $236-276$ & $258.0(4.4)$ & 0.833 & 0.039 \\
\hline B. saida & 53 & 37 & $252-448$ & $348.6(6.3)$ & 0.566 & $0.422^{\mathrm{c}}$ \\
\hline
\end{tabular}

(Hedrick, 2005), based on ratios of heterozygosities adjusted to account for the amount of genetic variation observed at each locus, was estimated with the software program SMOGD, vers. 1.2.5 (Crawford, 2010). Estimates of chord distances (Cavalli-Sforza and Edwards, 1967), a geometric measure, were made with PHYLIP, vers. 3.6 (Felsenstein, 2005).

Principal component analysis was used to contrast the genetic compositions of species groups (SYTAT, vers. 13 software; SYSTAT Software, Inc., San Jose, CA). Correlation matrix-based PCA standardizes variables so that each variable has a similar scale; it was used to contrast the allelic compositions. Covariance matrix-based PCA applies the observed variances so that the scale of variation is included in the analysis; it was used to contrast allele-frequency profiles. Loci missing from a collection or a species did not contribute to the PCA score.

Assignment tests (GeneClass2; Piry et al., 2004) were used to evaluate the robustness of the differences among species groups. The tests removed each individual fish from the species groups before assignment. The criterion of Rannala and Mountain (1997) was applied in all tests.

\section{Results}

Only genotypes from loci that could be reliably interpreted were analyzed in for each species. Nine loci am- 


\begin{tabular}{|c|c|c|c|c|c|c|}
\hline \multicolumn{7}{|c|}{ Table 2 (cont.) } \\
\hline Locus and species & $n$ & $n_{\mathrm{a}}$ & range & mean & $H_{\mathrm{e}}$ & $F_{\text {is }}$ \\
\hline \multicolumn{7}{|l|}{ Elgr13 } \\
\hline Chukchi Sea E. gracilis & 30 & 12 & $230-286$ & $251.1(1.3)$ & 0.867 & 0.007 \\
\hline GOA $E$. gracilis & 41 & 10 & $226-286$ & $254.3(1.4)$ & 0.805 & 0.006 \\
\hline E. nawaga & 81 & 19 & $214-286$ & $243.8(1.3)$ & 0.926 & -0.009 \\
\hline$M$. proximus & 22 & 19 & $242-338$ & $284.5(3.7)$ & 0.909 & 0.040 \\
\hline G. macrocephalus & 14 & 14 & $250-346$ & $314.7(4.3)$ & 1.000 & -0.093 \\
\hline G. chalcogrammus & 6 & dna & - & - & - & - \\
\hline B. saida & 53 & 12 & $206-318$ & $250.8(1.0)$ & 0.830 & -0.064 \\
\hline \multicolumn{7}{|l|}{ Elgr14 } \\
\hline Chukchi Sea $E$. gracilis & 30 & 14 & $322-378$ & $347.6(1.7)$ & 0.800 & 0.101 \\
\hline GOA $E$. gracilis & 41 & 9 & $330-370$ & $345.7(1.1)$ & 0.829 & -0.007 \\
\hline E. nawaga & 81 & 12 & $318-362$ & $329.4(0.7)$ & 0.790 & -0.010 \\
\hline$M$. proximus & 22 & 11 & $326-370$ & $340.3(1.6)$ & 0.682 & 0.217 \\
\hline G. macrocephalus & 14 & 4 & $314-346$ & $325.6(0.9)$ & 0.143 & $0.667^{\mathrm{b}}$ \\
\hline G. chalcogrammus & 6 & 10 & $330-418$ & $364.7(7.2)$ & 1.000 & -0.035 \\
\hline B. saida & 53 & 19 & $290-366$ & $325.5(1.7)$ & 0.811 & 0.121 \\
\hline \multicolumn{7}{|l|}{ Elgr44 } \\
\hline Chukchi Sea E. gracilis & 30 & 14 & $212-264$ & $240.9(1.7)$ & 0.867 & 0.057 \\
\hline GOA $E$. gracilis & 41 & 7 & $228-272$ & $247.1(1.1)$ & 0.537 & $0.161^{\mathrm{a}}$ \\
\hline E. nawaga & 81 & 14 & $216-268$ & $238.4(1.1)$ & 0.840 & 0.079 \\
\hline$M$. proximus & 22 & dna & - & - & - & - \\
\hline G. macrocephalus & 14 & dna & - & - & - & - \\
\hline G. chalcogrammus & 6 & dna & - & - & - & - \\
\hline B. saida & 53 & dna & - & - & - & - \\
\hline \multicolumn{7}{|l|}{ Elgr 45} \\
\hline Chukchi Sea $E$. gracilis & 30 & 13 & $205-265$ & $218.8(1.6)$ & 0.867 & 0.0085 \\
\hline GOA $E$. gracilis & 41 & 4 & $209-221$ & $213.0(0.4)$ & 0.683 & 0.0145 \\
\hline E. nawaga & 81 & 17 & $189-269$ & $224.5(1.2)$ & 0.864 & 0.0471 \\
\hline$M$. proximus & 22 & 6 & $197-217$ & $204.9(0.8)$ & 0.955 & -0.0769 \\
\hline G. macrocephalus & 14 & dna & - & - & - & - \\
\hline G. chalcogrammus & 6 & dna & - & - & - & - \\
\hline B. saida & 53 & dna & - & - & - & - \\
\hline \multicolumn{7}{|l|}{ Elgr23 } \\
\hline Chukchi Sea $E$. gracilis & 30 & 15 & $142-202$ & $170.5(1.8)$ & 0.933 & -0.027 \\
\hline GOA $E$. gracilis & 41 & 4 & $162-190$ & $168.1(0.4)$ & 0.683 & -0.181 \\
\hline E. nawaga & 81 & 17 & 138-214 & $168.1(1.1)$ & 0.926 & -0.019 \\
\hline$M$. proximus & 22 & 13 & 138-206 & $161.6(2.4)$ & 0.909 & -0.044 \\
\hline G. macrocephalus & 14 & 17 & $154-286$ & $215.0(5.0)$ & 0.929 & 0.034 \\
\hline G. chalcogrammus & 6 & 11 & $186-318$ & $246.7(12.6)$ & 1.000 & -0.017 \\
\hline B. saida & 53 & 23 & $138-258$ & $191.6(2.3)$ & 0.660 & $0.309^{\mathrm{c}}$ \\
\hline
\end{tabular}

plified reliably and had no apparent homozygote excess in E. gracilis (Table 2; Suppl. Table 1). However, not all loci that were reliable in $E$. gracilis amplified consistently and produced just 1 or 2 bands in all sets of samples. Most notably, Elgr38 did not amplify reliably in GOA samples of $E$. gracilis, nor was it reliable in $E$. nawaga. In addition, only 7 of the 9 loci worked well in $M$. proximus and only 5 in either $G$. chalcogrammus or B. saida. Again, Elgr38 did not amplify reliably in the GOA samples of $E$. gracilis nor was it reliable in $E$. nawaga. In addition, only 7 of the loci worked well in $M$. proximus and only 5 in each of $G$. chalcogrammus and $B$. saida. Of the loci that did not amplify reliably for a species group, several did produce bands. Only the loci that could be interpreted reliably were analyzed in each species.

\section{Comparisons of gadid collections}

Differences in ranges of allele sizes differentiated species and species groups (Table 2, Suppl. Fig. 1). For example, alleles at Elgr38 were on average much larger for B. saida and $G$. chalcogrammus than for the other species; alleles at Elgr31 were larger on average for $B$. saida and alleles at Elgr23 were on average larger for $G$. macrocephalus and G. chalcogrammus. The divergences in allele frequency size ranges were reflected in values of $D_{\text {chord }}$ and $G_{\text {ST }}^{\prime}$ (Table 3 ), all of which were 
significant (adjusted pairwise homogeneity tests $P<0.0001)$. The estimate of $G_{\text {ST }}^{\prime}$ between the two $E$. gracilis collections was smaller than values between all other gadid pairs; whereas the estimate of $D_{\text {chord }}$ was smaller than that of all but three of the comparisons of gadids, even though different suites of microsatellite loci were used. To provide a comparison of the extent of divergence between the two $E$. gracilis collections, values of $G_{\text {ST }}^{\prime}$ and $D_{\text {chord }}$ were estimated for the species pair Sebastes aleutianus and S. melanostictus from data in Gharrett et al. (2005), $G_{\mathrm{ST}}^{\prime}=0.551$ and $D_{\text {chord }}=0.064$. The estimate of $G_{\text {ST }}^{\prime}$ between the $E$. gracilis pair was lower (0.313) but the estimate of $D_{\text {chord }}$ was higher (0.078) than that between $S$. aleutianus and $S$. melanostictus, presumably because different algorithms were applied; $D_{\text {chord }}$ has a geometric basis and $G_{\text {ST }}^{\prime}$ is based on ratios of heterozygosities adjusted to account for the amount of genetic variation observed at each locus (Hedrick, 2005).

Individual-based PCA of allelic compositions (a correlation matrix) and allele frequency profiles (a covariance matrix) produced both speciesand collection-specific clusters (Fig. 1). The plot of the first and second components of the correlation-based PCA separated individual species more clearly, but separation of the two $E$. gracilis collections was not as strong. The covariance-based PCA clearly separated the two $E$. gracilis collections, but the other species were not separated quite as well. The first five components of the correlation-based analysis accounted for $10.6 \%$ and the first two components accounted for $5.1 \%$ of the overall variation in allelic composition. In contrast, the first five components of the covariance-based PCA accounted for $24.3 \%$ and the first two for $14.1 \%$ of the overall variation in allelic frequencies. Nevertheless, sufficient variation existed to separate these species and the two collections of $E$. gracilis.

A series of 4 tests was needed to estimate assignments of individuals because not all loci could be used for all species groups (Suppl. Table 2). The tests were the following: 1) all individuals were assigned on the basis of the three loci all groups had in common-Elgr14, Elgr23, and Elgr31; 2) the individuals scored in 1) as Chukchi Sea $E$. gracilis (CSC), GOA $E$. gracilis (GSC), E. nawaga (NAW), M. proximus
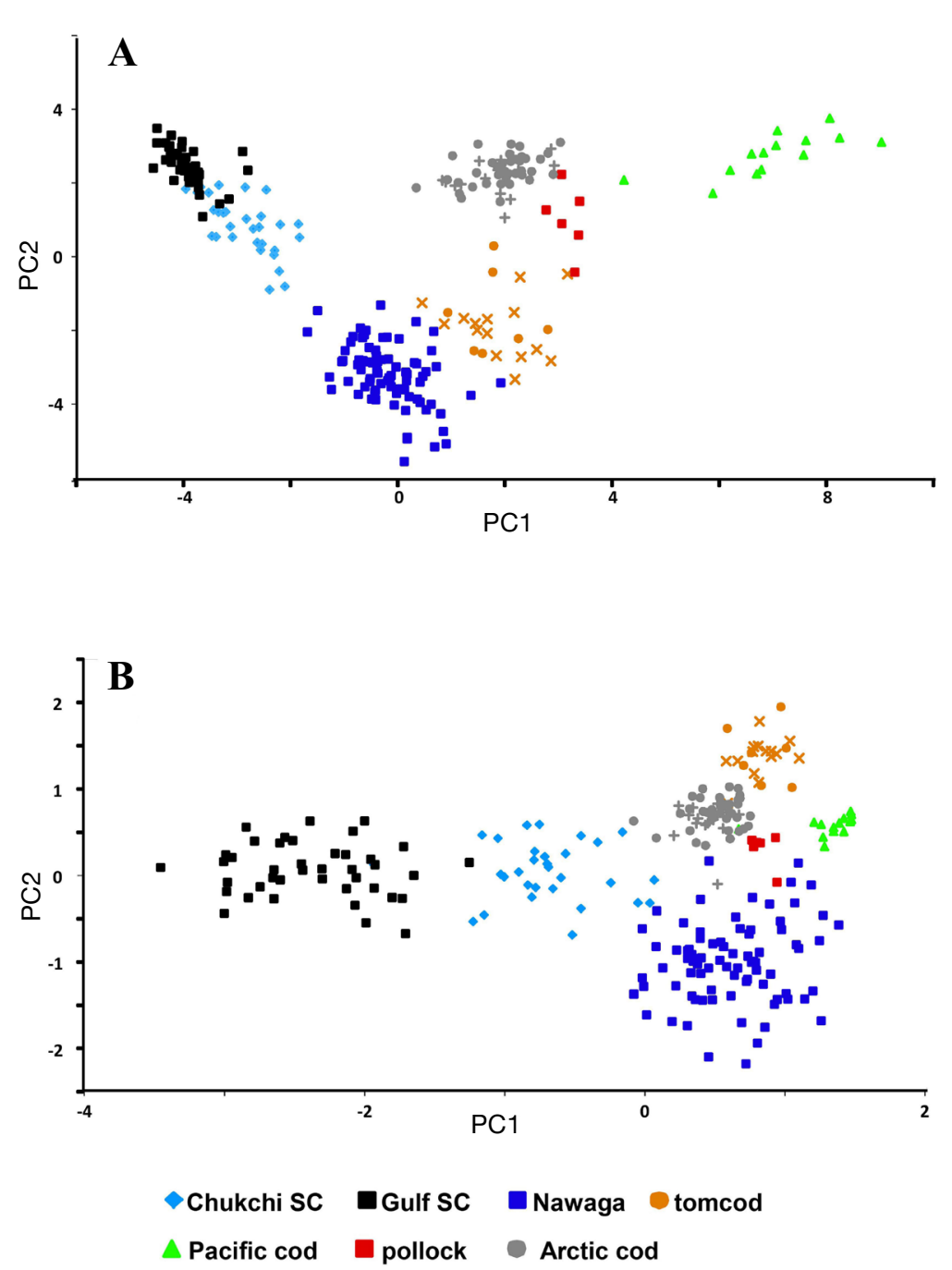

Figure 1

Results of principle component (PC) analyses. (A) Allele composition (a correlation matrix) and (B) allele frequency profiles (a covariance matrix) of microsatellite data from saffron cod (Eleginus gracilis [SC]) collected in the Chukchi Sea (Chukchi SC) and Gulf of Alaska (Gulf SC) in 2011 and 2013, navaga (E. nawaga) collected in the Barents Sea in 2013, Pacific tomcod (Microgadus proximus) collected in Puget Sound during 1997-1999 and in Prince William Sound in 2012, Pacific cod (Gadus macrocephalus) collected in Puget Sound and Unimak Pass in 2013, walleye pollock ( $G$. chalcogrammus) collected in the southeastern Bering Sea in 2015, and Arctic cod (Boreogadus saida) collected in the Chukchi Sea in 2012. The symbols ' + ' and ' $x$ ' denote individuals provided in saffron cod collections that were later re-identified as Arctic cod and Pacific tomcod, respectively. 


\section{Table 3}

Estimates of pairwise chord distances ( $D_{\text {chord}}$; above the diagonal) and standardized genetic differentiation measure ( $G_{\text {ST }}^{\prime}$, below the diagonal) for saffron cod (Eleginus gracilis) sampled in the Chukchi Sea and Gulf of Alaska (GOA) in 2011 and 2013 and for navaga (E. nawaga), Pacific tomcod (Microgadus proximus), Pacific cod (Gadus macrocephalus), walleye pollock (G. chalcogrammus), and Arctic cod (Boreogadus saida) sampled in the Pacific Rim and Arctic Ocean during 1997-2015. All estimates were significant (adjusted probabilities: $P<0.0001$ ). Values of average unbiased expected heterozygosity $\left(H_{\mathrm{e}}\right)$ are indicated in italic type on the diagonal.

\begin{tabular}{|c|c|c|c|c|c|c|c|}
\hline Collection & A & B & $\mathrm{C}$ & $\mathrm{D}$ & $\mathrm{E}$ & $\mathrm{F}$ & G \\
\hline A Chukchi Sea E. gracilis & 0.859 & $0.078^{\mathrm{a}}$ & $0.076^{\mathrm{a}}$ & $0.138^{\mathrm{a}}$ & $0.189^{b}$ & $0.218^{\mathrm{d}}$ & $0.076^{\mathrm{d}}$ \\
\hline B GOA $E$. gracilis & 0.313 & 0.689 & $0.130^{\mathrm{a}}$ & $0.183^{b}$ & $0.245^{\mathrm{b}}$ & $0.296^{\mathrm{e}}$ & $0.095^{\mathrm{e}}$ \\
\hline C E. nawaga & 0.414 & 0.680 & 0.863 & $0.093^{\mathrm{b}}$ & $0.137^{\mathrm{c}}$ & $0.158^{\mathrm{e}}$ & $0.069^{\mathrm{e}}$ \\
\hline D $M$. proximus & 0.603 & 0.779 & 0.565 & 0.733 & $0.182^{\mathrm{b}}$ & $0.228^{\mathrm{d}}$ & $0.088^{\mathrm{e}}$ \\
\hline E G. macrocephalus & 0.877 & 0.963 & 0.822 & 0.721 & 0.633 & $0.204^{\mathrm{d}}$ & $0.092^{\mathrm{e}}$ \\
\hline F G. chalcogrammus & 0.868 & 0.893 & 0.739 & 0.582 & 0.449 & 0.933 & $0.087^{\mathrm{e}}$ \\
\hline G B. saida & 0.599 & 0.680 & 0.584 & 0.781 & 0.681 & 0.607 & 0.766 \\
\hline
\end{tabular}

a 8 loci;

b 7 loci;

c 6 loci;

d 5 loci;

e 4 loci for both $D_{\text {chord }}$ and $G_{\text {ST }}^{\prime}$ estimates.

Elgr23, Elgr31, and Elgr38. The results of 3) and 4) assigned each individual to its own group, except 1 CSC (96.7\% of the total) and $1 \mathrm{ACO}(98.1 \%$ of the total) (Table 4).

Previous molecular studies have recognized G. macrocephalus, G. chalcogrammmus, and $B$. saida as distinct species (Coulson et al., 2006, Carr et al., 1999) but the systematic relationships among $E$. gracilis, $E$. nawaga, and $M$. proximus are still unresolved (Mecklenburg et al., 2016). Differences in the allele frequency profiles are easier to see in plots that include only those four groups (Table 2, Suppl. Fig. 2). The $M$. proximus and $E$. nagawa distributions clearly differ from those of the $2 \mathrm{E}$. gracilis collections at Elgr07 and Elgr11. The profiles for $M$. proximus and $E$. naga$w a$ clearly differ from those for the 2 collections of $E$. gracilis at Elgr07 and Elgr11. M. proximus also differs at Elgr13 and Elgr31 and has a substantially higher number of large alleles. The numbers of observed alleles (Table 2) in the collection of GOA $E$. gracilis are relatively lower than those of the others and several are more abundant (Suppl. Fig. 2), which is consistent with the somewhat lower heterozygosity (Table 2) of the GOA E. gracilis.

\section{Discussion}

Eight of the nine microsatellites that were evaluated for two collections of $E$. gracilis and that amplified reliably were variable (heterozygosities 0.537 to 0.933 ) and had no apparent homozygote excess, indicating low null allele frequencies. The single exception, Elgr38, amplified reliably for the Chukchi Sea collection of $E$. gracilis but not for the GOA collection. At the other loci, the two collections had similar allele size ranges but differed substantially in allele frequencies $\left(G_{\mathrm{ST}}^{\prime}=0.313\right.$, $\left.D_{\text {chord }}=0.078, P<0.0001\right)$. The observed differences were similar to those between two cryptic rockfish species that had overlapping ranges, $S$. aleutianus and $S$. melanostictus, although they were estimated with different suites of loci. In the PCA plots, individuals from the two collections of $E$. gracilis were mostly distinct from each other, particularly in the analysis of the covariance matrix, which focuses on the allele frequencies rather than allele composition. It is also notable that the PCA analyses included frequency differences of the other gadids analyzed, and differences between the 2 collections of $E$. gracilis were evident against the background variation from other species.

Assignment tests placed all but one saffron cod in the group from which it originated. Not all nine microsatellite loci amplified reliably in all of the other gadid species analyzed and some had an excess of homozygotes, most likely as a consequence of null alleles; those loci were not used for assignment tests. Nevertheless, where comparisons were possible, all the other gadids differed in microsatellite composition $(P<0.0001)$ from both collections of $E$. gracilis and each other. The correlation matrix-based PCA, in particular, clustered individuals according to species or geographic groups of species. The PCA analyses turned out to be valuable in analyzing a large set of samples of putative $E$. gracilis because the analysis revealed outliers that, when compared with the clusters of other gadids, enabled detection of individuals misidentified as E. gracilis. Two 


\begin{tabular}{|c|c|c|c|c|c|c|c|c|}
\hline \multicolumn{9}{|c|}{ Table 4} \\
\hline \multicolumn{9}{|c|}{$\begin{array}{l}\text { Summary of results of a series of tests (Piry et al., 2004) that assigned each fish to } 1 \text { of } 7 \text { species groups } \\
\text { saffron cod (Eleginus gracilis) of the Chukchi Sea (CSC), saffron cod of the Gulf of Alaska (GSC), navaga } \\
\text { (E. nawaga) (NAW), Pacific tomcod (Microgadus proximus) (PTC), Pacific cod (Gadus macrocephalus) } \\
\text { (PCO), walleye pollock (G. chalcogrammus) (WPO), and Arctic cod (Boreogadus saida) (ACO). } n=\text { the } \\
\text { number of individuals of each group. For all results from the assignment tests, see Supplementary } \\
\text { Table } 2 \text {. }\end{array}$} \\
\hline \multirow[b]{2}{*}{$n$} & \multirow[b]{2}{*}{ Species group } & \multicolumn{7}{|c|}{ Assigned to } \\
\hline & & $\mathrm{CSC}$ & GSC & NAW & PTC & $\mathrm{PCO}$ & WPO & $\mathrm{ACO}$ \\
\hline 30 & $\mathrm{CSC}$ & 29 & $1^{\mathrm{a}}$ & 0 & 0 & 0 & 0 & 0 \\
\hline 41 & GSC & 0 & 41 & 0 & 0 & 0 & 0 & 0 \\
\hline 81 & NAW & 0 & 0 & 81 & 0 & 0 & 0 & 0 \\
\hline 23 & PTC & 0 & 0 & 0 & 23 & 0 & 0 & 0 \\
\hline 14 & $\mathrm{PCO}$ & 0 & 0 & 0 & 0 & 14 & 0 & 0 \\
\hline 6 & WPO & 0 & 0 & 0 & 0 & 0 & 6 & 0 \\
\hline 53 & $\mathrm{ACO}$ & 0 & 0 & 0 & 0 & 0 & $1^{\mathrm{b}}$ & 52 \\
\hline
\end{tabular}

notable instances were 14 aberrant genotypes included in a collection of $E$. gracilis from the Chukchi Sea and another 15 in a collection of $E$. gracilis from Prince William Sound. In both instances, it was possible to re-examine the individual specimens; the former were re-identified as $B$. saida and the latter as $M$. proximus (Table 1). Both sets of re-identified individuals were included with their correct species in the analyses presented here (designated as ' + ' and ' $x$ ', respectively in Fig. 1). Assignment tests correctly reassigned all of the other gadids except one Arctic cod.

In these analyses, the two collections of $E$. gracilis, and the collections of $M$. proximus, and $E$. nawa$g a$ were all distinct from each other $(P<0.0001)$. The degree of their divergences mostly exceeded those observed between $S$. aleutianus and $S$. melanostictus (Gharrett et al., 2005) and each of the collections clustered separately in PCAs. It is notable that misidentified individuals of Prince William Sound $M$. proximus were collected at the same site with E. gracilis, but were genetically distinct from them. Clearly, some field identifications, even by trained personnel, are challenging (cf. Teletchea, 2009). It is unlikely that they represent two sympatric populations of a single marine species-populations that are so strongly different genetically. Although it could be argued that the genetic differences between the collections of $E$. nawaga and $E$. gracilis could result from divergence over the large distance that separates them, the very large divergences in allele frequencies, as well as similar differences in allele size ranges at Elgr 11 and Elgr14, are more consistent with their being distinct species. More complete information on the modern Arctic distributions of the two species of Eleginus, and the location of the historic contact zone between them, would contribute to re- solving their systematic status, as would independent data, such as mitogenomic sequences of $E$. nawaga and $E$. gracilis, coupled with morphological characters (Teletchea, 2009).

\section{Acknowledgements}

Funding was provided by the U.S. Department of Interior (Bureau of Ocean Energy Management Agreements M12AC00009 and M12AC00009), the U.S. Department of the Interior (Fish and Wildlife Service Agreements 10-CIAP-010 and F12AF00188), the Department of Energy (award no. DE-FC09-07SR22506), and the Russian Federation for Fundamental Investigations (Grant15-04-02081, Gostema no. 01201351186). This article is contribution EcoFOCI-0896 to NOAA's Ecosystems and Fisheries Oceanography Coordinated Investigations program.

\section{Literature cited}

Benjamini, Y., and Y. Hochberg.

1995. Controlling the false discovery rate: a practical and powerful approach to multiple testing. J. R. Stat. Soc., B. 57:289-300. Article

Bluhm, B. A., and R. Gradinger.

2008. Regional variability in food availability for arctic marine mammals. Ecol. Appl. 18:S77-S96. Article

Castoe, T. A., A. W. Poole, A. P. J. de Koning, K. L. Jones, D. F. Tomback, S. J. Oyler-McCance, J. A. Fike, S. L. Lance, J. W. Streicher, E. N. Smith, and D. D. Pollack.

2012. Rapid microsatellite identification from Illumina paired-end genomic sequencing in two birds and a snake. PLoS ONE 7(2):e30953. Article 
Cavalli-Sforza, L. L, and A. W. F. Edwards.

1967. Phylogenetic analysis: models and estimation procedures. Evolution 21:550-570. Article

Crawford, N. G.

2010. SMOGD: software for the measurement of genetic diversity. Mol. Ecol. Resour. 10:556-557.

Carr, S. M., and H. D. Marshall.

2008. Phylogeographic analysis of complete mtDNA genomes from Walleye Pollock (Gadus chalcogrammus Pallas, 1811) shows an ancient origin of genetic biodiversity. DNA Sequence 19:490-496. Article

Carr, S. M., D. S. Kivlichan, P. Pepin, and D. C. Crutcher. 1999. Molecular systematics of gadid fishes: implications for the biogeographic origins of Pacific species. Can. J. Zool. 77:19-26. Article

Cohen, D. M. (ed.).

1989. Papers on the systematics of gadiform fishes. Nat. Hist. Mus. Los Ang. Cty., Sci. Ser. 32, 262 p.

Cohen, D. M., T. Inada, T. Iwamoto, and N. Scialabba.

1990. FAO species catalogue, vol. 10. Gadiform fishes of the world (Order Gadiformes). An annotated and illustrated catalogue of cods, hakes, grenadiers and other gadiform fishes known to date. FAO Fisheries Synopsis 125,442 p. FAO, Rome.

Copeman, L. A., B. J. Laurel, K. M. Boswell, A. L. Sremba,

K. Klinck, R. A. Heintz, J. Vollenweider, T. E. Helser, and

M. L. Spencer.

2016. Ontogenetic and spatial variability in trophic biomarkers of juvenile saffron cod (Eleginus gracilis) from the Beaufort, Chukchi and Bering Seas. Polar Biol. 39:1109-1126. Article

Coulson, M. W., H. D. Marshall, P. Pepin, and S. M. Carr.

2006. Mitochondrial genomics of gadine fishes: implications for taxonomy and biogeographic origins from wholegenome data sets. Genome 49:1115-1130. Article

DeWoody, J. A., and J. C. Avise.

2000. Microsatellite variation in marine, freshwater and anadromous fishes compared with other animals. J. Fish Biol. 56:461-473. Article

Don, R. H., P. T. Cox, B. J. Wainwright, K. Baker, and J. S. Mattick.

1991. 'Touchdown' PCR to circumvent spurious priming during gene amplification. Nucleic Acids Res. 19:4008. Article

Felsenstein, J.

2005. PHYLIP (Phylogeny Inference Package), vers. 3.6. Dep. Genome Sci., Univ. Washington, Seattle, WA. [Available from website.]

Gharrett, A. J., A. P. Matala, E. L. Peterson, A. K. Gray, and

Z. Li.

2005. Two genetically distinct forms of rougheye rockfish are different species. Trans. Am. Fish. Soc. 134:242260. Article

Harpending, H. C, M. A. Batzer, M. Gurven, L. B. Jorde, A. R. Rogers, and S. T. Sherry.

1998. Genetic traces of ancient demography. Proc. Natl. Acad. Sci. U.S.A. 95:1961-1967. Article

Hedrick, P. W.

2005. A standardized genetic differentiation measure. Evolution 59:1633-1638. Article

Kamin, L. M., K. J. Palof, J. Heifetz, and A. J. Gharrett. 2014. Interannual and spatial variation in the population genetic composition of young-of-the-year Pacific ocean perch (Sebastes alutus) in the Gulf of Alaska. Fish. Oceanogr. 23:1-17. Article

Koressaar, T., and M. Remm.

2007. Enhancements and modifications of primer design program Primer3. Bioinformatics 23:1289-1291. Article

Mecklenburg, C. W., T. A. Mecklenburg, B. A. Sheiko, and D. Steinke.

2016. Pacific Arctic marine fishes, 375 p. Conservation of Arctic Flora and Fauna, Akureyri, Iceland.

Piry, S., A. Alapetite, J.-M. Cornuet, D. Paetkau, L. Baudouin, and A. Estoup.

2004. GENECLASS2: A software for genetic assignment and first-generation migrant detection. J. Hered. 95:536-539. Article

Rannala, B., and J. L. Mountain.

1997. Detecting immigration by using multilocus genotypes. Proc. Natl. Acad. Sci. U.S.A. 94:9197-9201. Article

Rice, W. R.

1989. Analyzing tables of statistical tests. Evolution 43:223-225. Article

Roa-Varón, A., and G. Ortí.

2009. Phylogenetic relationships among families of Gadiformes (Teleostei, Paracanthopterygii) based on nuclear and mitochondrial data. Mol. Phylogen. Evol. 52:688-704. Article

Rousset, F.

2008. GENEPOP'007: a complete re-implementation of the GENEPOP software for Windows and Linux. Mol. Ecol. Resour. 8:103-106. Article

Schultz, L. P., and A. D. Welander.

1935. A review of the cods of the northeastern Pacific with comparative notes on related species. Copeia 1935:127139. Article

Seutin, G., B. N. White, and P. T. Boag.

1991. Preservation of avian blood and tissue samples for DNA analysis. Can. J. Zool. 69:82-90. Article

Stoutamore, J. L., C. N. Love, S. L. Lance, K. L. Jones, and D. Tallmon.

2012. Development of polymorphic microsatellite markers for blue king crab (Paralithodes platypus). Conserv. Genet. Resour. 4:897-899. Article

Svetovidov, A. N.

1948. Gadiformes (Treskoobraznye). Fauna of the U.S.S.R., vol. 9, no. 4, 304 p. Israel Program Sci. Transl., Jerusalem, Israel.

Teletchea, F.

2009. Molecular identification methods of fish species: reassessment and possible applications. Rev. Fish Biol. Fish. 19:265-293. Article

Teletchea, F., V. Laudet, and C. Hännia.

2006. Phylogeny of the Gadidae (sensu Svetovidov, 1948) based on their morphology and two mitochondrial genes. Mol. Phylogen. Evol. 38:189-199. Article

Untergasser, A., I. Cutcutache, T. Koressaar, J. Ye, B. C. Faircloth, M. Remm, and S. G. Rozen.

2012. Primer3-new capabilities and interfaces. Nucleic Acids Res. 40:e115. Article

Wolotira, R. J., Jr.

1985. Saffron cod (Eleginus gracilis) in western Alaska, the resource and its potential. NOAA Tech. Memo. NMFS F/NWC-79, 119 p. 